\title{
SIMULASI MONTE CARLO UNTUK MODEL ISING 2D PADA KISI BUJUR SANGKAR MENGGUNAKAN ALGORITMA METROPOLIS
}

\author{
Marliana Lutan $^{1 \mathrm{a}}$, Momang Yusuf ${ }^{2 \mathrm{~b}}$, Kurniati Abidin ${ }^{3 \mathrm{c}}$, Nursakinah Annisa Lutfin ${ }^{4 \mathrm{~d}}$, dan Nurlina ${ }^{5 \mathrm{e}}$ \\ ${ }^{1,2.3}$ Insitut Teknologi Bandung, ${ }^{4,5}$ Universitas Sulawesi Barat \\ Email*: ․ㅡarliana.lutan@gmail.com, ${ }^{b}$ momangyusuf@unm.ac.id, ${ }^{c}$ kurniati.abidin@ uin-alauddin.ac.id, \\ dnursakinalutfin@unsulbar.ac.id, enurlina@usulbar.ac.id
}

Abstrak

Telah dilakukan penelitian tentang Simulasi Monte Carlo untuk Model Ising 2D pada Kisi Bujur Sangkar dengan Interaksi Nearest Neighbor and Next NN menggunakan Algoritma Metropolis. Simulasi ini bertujuan untuk menunjukan proses transisi fase dari material feromagnetik menjadi paramagnetik. Model ini dideskripsikan sebagai sistem spin dengan panjang kisi $20 \times 20$. Hasil simulasi menunjukkan bahwa spin akan semakin acak saat terjadi kenaikan temperatur. Pada magnetisasi maksimum untuk material ferromagnetik, temperatur dan energi berada pada keadaan rendah. Magnetisasi menurun secara drastis pada temperatur dan energi tertentu, kemudian hilang karena material telah bersifat paramagnetik. Hasil ini menunjukkan bahwa magnetisasi bergantung pada temperatur dan energi material.

Kata kunci: Monte Carlo, Ising 2D, Algoritma Metropolis, Magnetisasi, Temperatur, Energi.

\section{MONTE CARLO SIMULATION FOR 2D ISING MODEL ON SQUARE GRID USING METROPOLIS ALGORITHM}

\author{
Abstract
}

Research has been done on Monte Carlo Simulation for 2D Ising Models on a Square Grid with Nearest Neighbor and Next NN Interaction using the Metropolis Algorithm. This simulation aims to show the phase transition process from ferromagnetic to paramagnetic materials. This model is described as a spin system with a lattice length of $20 \times 20$. The simulation results show that the spin will be more random when the temperature increases. At the maximum magnetization for ferromagnetic materials, the temperature and energy are at a low state. Magnetization decreases drastically at a certain temperature and energy, then disappears because the material has become paramagnetic. These results indicate that the magnetization depends on the temperature and energy of the material.

Keywords: Monte Carlo, Ising 2D, Metropolis Algorithm, Magnetization, Temperature, Energy.

\section{PENDAHULUAN}

Ferromagnetisme adalah fenomena fisika zat padat yang menarik untuk diamati. Gejala feromagnetik muncul dari sejumlah atom dengan spin-spin yang memiliki arah yang sama. Arah dari spin-spin ini menentukan magnetisasi dari sebuah material. Jika terdapat banyak spin yang memiliki arah yang sama maka magnetisasinya besar, sebaliknya jika keadaan spinnya sebanding antara yang searah dan berlawanan maka magnetisasinya kecil. Deskripsi teoritis paling sederhana dari feromagnetisme disebut model Ising. Model ini ditemukan oleh Wilhelm Lenz pada tahun 1920 dan dinamai Ernst Ising [3], seorang mahasiswa Lenz yang memilih model ini sebagai subjek disertasi doktornya pada tahun 1925. Model Ising adalah model interaksi 
sederhana antara spin dalam material yang dapat menunjukkan fase transisi dari ferromagnetik [4]

Paper ini akan melaporkan hasil simulasi proses magnetisasi spin model Ising 2D. Magnetisasi dalam simulasi model Ising 2D ini diperoleh dari nilai rata-rata keadaan mikroskopis material. Karena jumlahnya sangat banyak, maka akan sulit untuk menghitung masing-masing nilainya, sehingga perlu dilakukan sampling secara acak dengan menggunakan metode Monte Carlo yang melibatkan algoritma metropolis.

\section{Model Ising 2 Dimensi}

Model Ising pertama kali dikembangkan oleh Ising untuk menjelaskan sifat magnetik bahan dengan memandang bahan tersusun atas momen-momen magnetik yang tersusun secara teratur [1]

Model Ising adalah model standar fisika statistik yang memberikan deskripsi mikroskopis feromagnetisme sederhana. Model Ising menjelaskan transisi fase feromagnetik dari fase paramagnetik pada suhu tinggi ke fase feromagnetik di bawah suhu Curie $T_{C}$. Berbagai macam teknik dan metode dalam fisika statistik awalnya telah dirumuskan untuk model Ising dan digeneralisasikan sesuai dengan model dan masalah terkait [6].

Model Ising pada awalnya diterapkan Ising untuk menyelesaikan kasus ferromagnet 1 dimensi, namun model 1D ini tidak dapat menunjukkan terjadinya perubahan fase pada bahan. Onsager kemudian mengembangkan model tersebut pada dimensi yang lebih tinggi dan ternyata menunjukkan adanya perubahan fase [7].

Model Ising merupakan bentuk penyederhanaan dari model Heisenberg. Model Ising mempertimbangkan jumlah titik kekisi $N$ dan berasumsi bahwa setiap titik kekisi memiliki keterkaitan dengan spin $(\sigma)$, dengan $\sigma= \pm 1$. Sifat makroskopik sistem dapat ditentukan dari sifat mikroskopiknya, oleh karena itu perlu diketahui nilai energi yang bergantung konfigurasi spin yaitu:

$$
\widehat{H}=-J \sum_{<i j>} \quad \sigma_{i} \sigma_{j}-B \sum_{i} \quad \sigma_{i}(1)
$$

Besarnya magnetisasi dapat ditentukan dari:

[2].

$$
M=\sum_{<i j>} \quad \sigma_{i j}
$$

Perubahan energi untuk nearest neighbor dapat dicari dengan:

$$
\begin{aligned}
& E=-\sigma_{i, j}\left(\sigma_{i+1, j}+\sigma_{i-1, j}+\sigma_{i, j+1}+\right. \\
& \left.\sigma_{i, j-1}\right)
\end{aligned}
$$

Sedangkan untuk kasus next nearest neighbor dapat dicari dengan:

$$
\begin{gathered}
E=-\sigma_{i, j}\left(\sigma_{i+1, j}+\sigma_{i-1, j}+\sigma_{i, j+1}+\sigma_{i, j-1}+\right. \\
\left.\sigma_{i-1, j+1}+\sigma_{i-j, j-1}+\sigma_{i+1, j-1}+\sigma_{i+1, j+1}\right)
\end{gathered}
$$

Ferromagnetik memiliki spin dengan arah yang sama sebanyak titik kekisi $N$, pada paramagnetik spin menunjuk arah berlawanan sebanyak titik kekisi $N$. Uraian tersebut adalah dasar dalam model Ising untuk ferromagnetik dan paramagnetik.

Secara matematis, untuk menghitung nilai energi pada model Ising diberikan pada Persamaan (1). Dalam perhitungan energi, keduanya mempertimbangkan nilai interaksi tukar $J$ yang merupakan ukuran kekuatan interaksi antara spin dengan tetangga terdekatnya. Jika $J>0$, pada keadaan spin $\uparrow \uparrow$ dan $\downarrow \downarrow$ energi yang terjadi lebih besar dibandingkan dengan keadaan $\uparrow \downarrow$ dan $\downarrow \uparrow$. Keadaan ini terdapat pada ferromagnetik, karena spin pada semua titik kekisi memiliki arah yang sama. Jika $J<0$, pada keadaan spin $\uparrow \downarrow$ dan $\downarrow \uparrow$, energi yang dimiliki rendah. Ini merupakan keadaan paramagnetik karena arah spin saling berlawanan.

\section{Metode Monte Carlo}

Monte Carlo adalah metode pemecahan masalah secara numerik yang sulit diselesaikan secara analitik. Metode Monte Carlo merupakan metode pencarian acak, tetapi dengan beberapa perbaikan, yaitu tidak semua nilai pada solusi diacak ulang, tetapi dipilih satu nilai saja diantara barisan nilai solusi dan kemungkinan acak dari setiap kejadian solusio [8]. Monte Carlo adalah prosedur untuk menguji suatu sistem secara acak sesuai dengan jumlah step dan iterasi yang sudah ditentukan [9]. Bila pada solusi hanya mengandung satu nilai saja maka metode Monte Carlo ini sama dengan metode pencarian acak.

Metode Monte Carlo dimungkinkan untuk bisa menyelesaikan masalah untuk kasus model Ising ini. Sebuah proses yang ditandai dengan proses acak. Algoritma yang digunakan adalah prinsip sampling Metropolis.

Algoritma untuk melengkapi teori random dari metode Monte Carlo. Metropolis sepakat 
bahwa kebanyakan dari sistem di alam tidak terisolasi. Pertukaran energi antara sistem dengan lingkungan akan terjadi hingga diperoleh kesetimbangan antara keduanya. Jika terdapat banyak sistem pada volume $V$ dan terdapat jumlah partikel sebanyak $N$, kondisi tersebut setimbang pada temperatur $T$, sistem berada pada keadaan $s$ dan memiliki energi $E s$, maka probabilitasnya dinyatakan sebagai berikut [5].

$$
P_{S}=e^{-\beta E_{S}}
$$

dengan $\beta=\left(k_{B} T\right)^{-1}, k_{B}$ merupakan konstanta Boltzmann dan $T$ adalah temperatur.

\section{METODE}

Keadaan awal spin setiap sel ditentukan secara acak. Keadaan acak diperoleh dengan cara membangkitkan satu bilangan acak. Jika bilangan acak yang diperoleh bernilai lebih besar dari 0,5 maka spin di sel itu ditentukan bernilai +1 dan sel diberi warna putih. Jika bilangan acak bernilai kurang dari 0,5 maka spin di sel itu ditentukan bernilai -1 dan sel diberi warna hitam.

Langkah-langkahnya menggunakan algoritma metropolis dengan lembar kerja excel, sebagai berikut: Inisialisasi spin di kisi awal dengan semua spin down. Untuk tiap spin $i$ di dalam kisi: Membuat konfigurasi baru dengan membalik spin $S_{i}$. Melakukan perhitungan perubahan energi sistem $d E=E_{\text {baru }}-E_{\text {lama }}$. Untuk $d E<0$, terima perubahan (spin dibalik), kelangkah $e$. Untuk $d E>0$, bangkitkan bilangan acak $0<\eta<1$, terima perubahan jika $e^{-\frac{d E}{d T}}>\eta$. Diulang sebanyak pengulangan yang diinginkan [10].

Metode numerik dapat digambarkan dengan jelas pada flowchart di bawah ini.

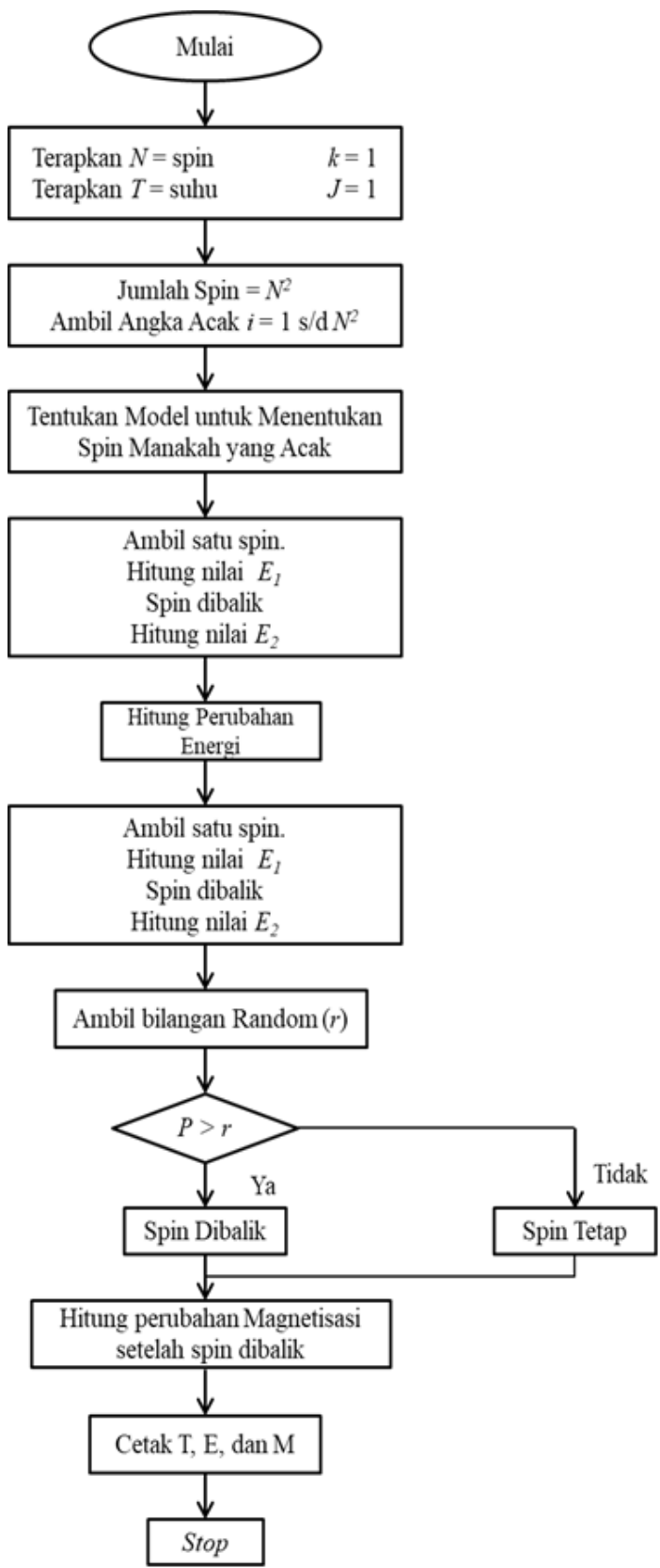

Gambar 1. Flowchart Algoritma Metropolis. 


\section{HASIL DAN PEMBAHASAN}

Implementasi simulasi Monte Carlo dengan algoritma Metropolis dari sistem Ising 2D telah dilakukan dengan menggunakan program MatLab. Penelitian ini mempelajari tentang dinamika kisi dua dimensi. Pembahasan hanya dibatasi pada bagian magnetisasi yang dipengaruhi oleh jumlah interaksi spin didalam kisi 2D. Sebaran dari kondisi/probabilitas spin (up atau down), disimulasikan dengan pola magnetisasi hitam untuk spin up dan putih untuk spin down.

Untuk keperluan simulasi, dipilih kekuatan interaksi $J=1$, konstanta Boltzmann, $k=1$ dan grid $20 \times 20$. Hasil simulasi diberikan oleh gambar berikut:
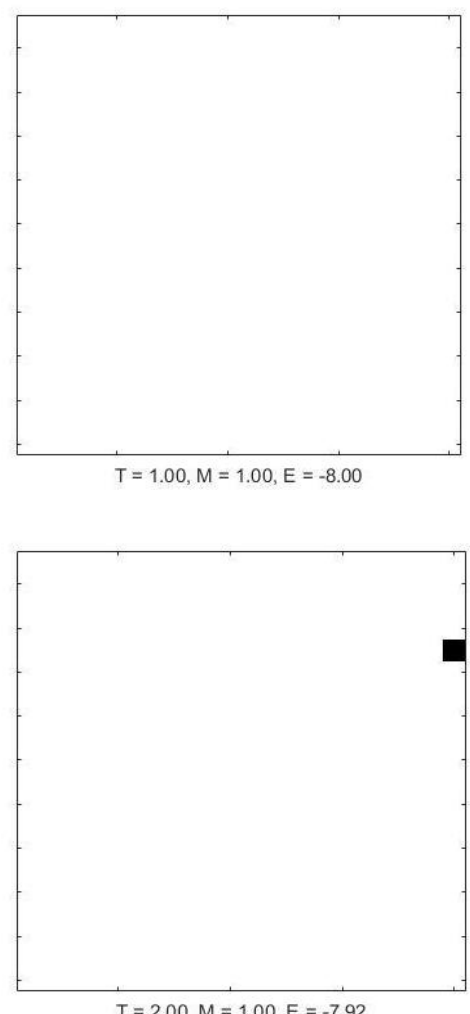

$\mathrm{T}=2.00, \mathrm{M}=1.00, \mathrm{E}=-7.92$

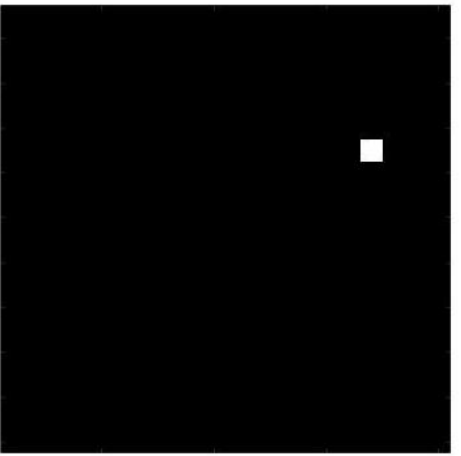

$\mathrm{T}=3.00, \mathrm{M}=1.00, \mathrm{E}=-7.92$

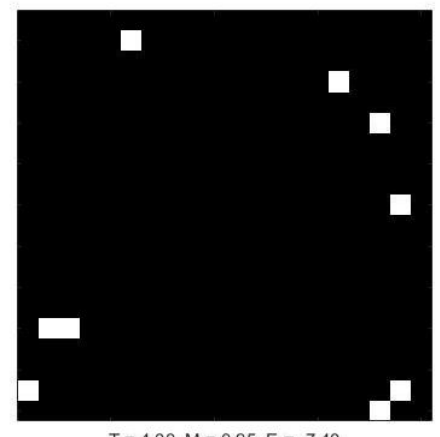

$\mathrm{T}=4.00, \mathrm{M}=0.95, \mathrm{E}=-7.40$
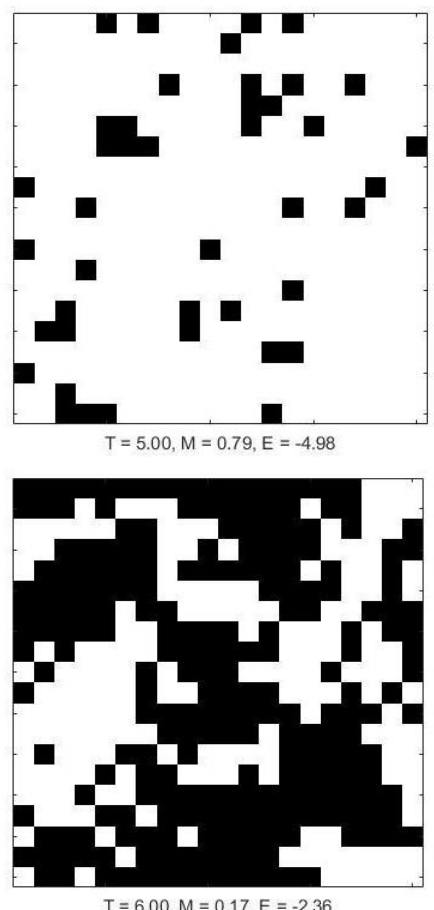


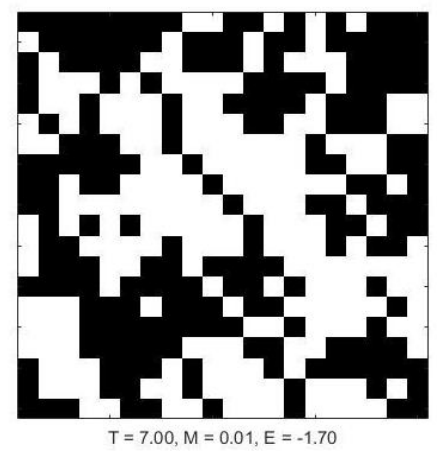

Gambar 2. Hasil Simulasi Model Ising 2D dengan Iterasi 1000 pada temperatur tertentu.

Pada temperatur cukup rendah, semua spin dalam model Ising 2D akan bekerja sama dan secara spontan mensejajarkan diri mereka sendiri (misalnya sebagian besar spin menjadi +1 ) bahkan tanpa kehadiran medan luar $(h=0)$. Fenomena ini disebut magnetisasi spontan atau ferromagnetik. Ketika temperatur dinaikkan, beberapa spin akan mulai terbalik sampai mencapai temperatur kritis yang disebut temperatur Curie. Setelah itu, orientasi spinnya akan menjadi random dan material akan bersifat paramagnetik.

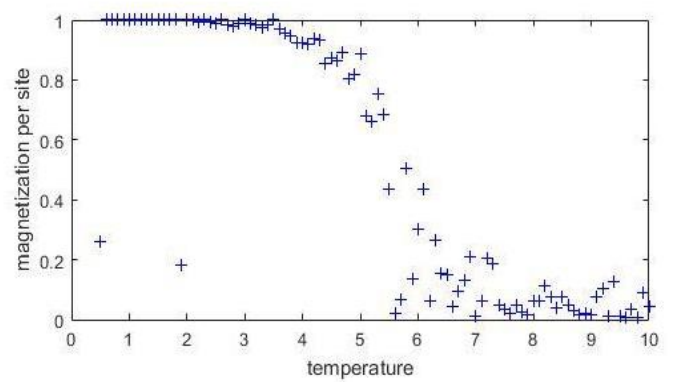

Gambar 3. Grafik hubungan antara magnetisasi dengan temperatur.

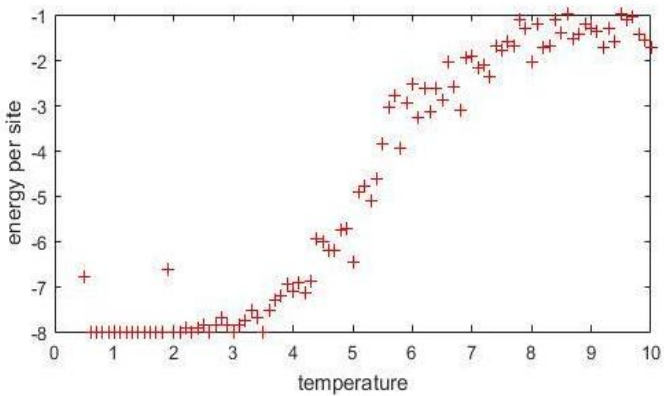

Gambar 4. Grafik hubungan antara energi dengan temperatur.

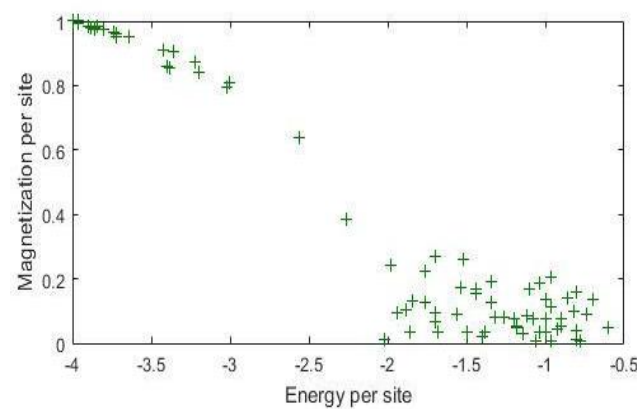

Gambar 5. Grafik hubungan antara magnetisasi dengan energi.

Pada Gambar 3, grafik magnetisasi terhadap temperatur, nilai magnetisasinya maksimum $(M=1)$, dimana material berada dalam keadaan ferromagnetik . Pada saat mencapai temperatur tertentu, nilai magnetisasinya mengalami penurunan yang drastis menuju nol sehingga material menjadi paramagnetik. Pada Gambar 4, grafik energi terhadap temperatur, nilai energinya minimum dan pada saat mencapai temperatur tertentu, nilai energinya mengalami peningkatan yang drastis. Pada Gambar 5, grafik hubungan antara magnetisasi dengan energi, nilai magnetisasi mengalami penurunan drastis terhadap kenaikan energi kemudian konstan.

\section{KESIMPULAN}

Simulasi menunjukkan bahwa spin akan semakin acak saat terjadi kenaikan temperatur. Pada temperatur tertentu, nilai magnetisasi akan mengalami penurunan yang drastis. Pada temperatur tertentu, nilai energi akan mengalami peningkatan yang drastis. Nilai magnetisasi mengalami penurunan drastis terhadap kenaikan energi.

\section{DAFTAR PUSTAKA}

[1] Abdullah, Mikrajuddin. 2015. Mekanika Statistik. Bandung: Fisika, FMIPA, ITB.

[2] D. Marchand. 2005. Classical Monte Carlo and the Metropolis Algorithm: Revisiting the 2D Ising Model. Department of Physics and Astronomy, University of British Columbia, Vancouver.

[3] E. Ising. 1925. Beitrag zur theorie des ferromagnetismus. Z. Phys. 31 (1925) 253258. 
[4] Fitzpatrick, Richard. 2006. Computational Physics: An introductory course. https://farside.ph.utexas.edu/teaching/329/le ctures/lectures.html

[5] N. Metropolis, Arianna W. Rosenbluth, Marshall N. Rosenbluth, Augusta H. Teller, and Edward Teller. 1953. Equation of State Calculations by Fast Computing Machines. The Journal of Chemical Physics, 21(6): 1087 - 1092.

[6] Preis, Tobias, Peter Virnau, Wolfgang Paul, Johannes J. Schneider. 2009. GPU accelerated Monte Carlo simulation of the $2 D$ and $3 D$ Ising model. Journal of Computational Physics, 228 (2009), 44684477.

[7] Safitri R. N., A. R. U. Fadlilah, D. Darmawan, R. Y. A. Sari. 2012. Kajian Sistem Terfrustasi pada Bahan Antiferromagnet dengan Model Ising 2D. Jurnal Sains Fisika dan Terapannya, Vol 1.

[8] Schmidt, Emanuel. 2011. Monte Carlo of the 2D Ising Model. http://www.emanuelschmidt.eu/physik/ising .pdf

[9] Septiani D, Iswanto BH, dan Sugihartono I, 2011. Studi Magnetisasi pada Sistem Spin menggunakan Model Ising 2D. Spektra:Jurnal Fisika dan Aplikasinya, Vol. XII.

[10] Sulistya E, 2012. Simulasi Model Ising 2 Dimensi dengan Algoritma Metropolis pada Lembar Kerja Excel. ISSN: 0853-0823. Prosiding Pertemuan Ilmiah XXVI HFI Jateng \& DIY. 